\title{
Trajetória de mobilidade e representações sociais do Timor-Leste pelas memórias de Inu Bere ${ }^{1}$
}

\author{
Sinorino Bere de Jesus ${ }^{2}$ \\ Lidiane Maria Maciel ${ }^{3}$
}

\begin{abstract}
Resumo: Este "ensaio-entrevista" é uma peça experimental coproduzida pelos autores que aqui assinalam o mesmo. A proponente da atividade, a socióloga Lidiane Maria Maciel, convida o jovem artista visual Inu Bere a reconstruir sua trajetória de mobilidade desde o Timor Leste até o Brasil. Nesta ocasião, o artista foi estimulado pelas questões da socióloga a reconstruir o passado de luta por independência de seu país por meio de sua história familiar e sua trajetória de mobilidade internacional. Ao leitor/a é cedido um espaço para atuação na busca da interpretação dos sentidos do que é exposto pelo depoente/autor. A participação da socióloga se realiza na elaboração das questões direcionadas ao entrevistado/autor e dos detalhamentos, quando necessários, para o preenchimento de certas lacunas, a fim de que o/a leitor/a possa expandir sua interpretação da trajetória.
\end{abstract}

Palavra-chave: Mobilidade estudantil. Colonialismo. Espaço de vida. Representações sociais. Timor-Leste.

\section{Trajectory of mobility and social representations of Timor-Leste through the memories of Inu Bere}

${ }^{1} \mathrm{O}$ trabalho se inspira, em primeiro lugar, nas provocações da produção de um conhecimento pós-colonial (SANTOS, 2010), que reconsidera as posturas científicas conhecidas e investe na proposição de uma nova abordagem epistêmica. $O$ trabalho também se pauta na proposta de entrevista compreensiva, conforme fez Bourdieu (1997) na obra A miséria do mundo.

2 Artista timorense (Inu Bere), graduando em Licenciatura em Artes da Faculdade de Educação e Artes da Universidade do Vale do Paraíba (UNIVAP). E-mail: inuartimor@gmail.com

3 Professora do Programa de Pós-graduação em Planejamento Urbano e Regional e da Faculdade de Educação e Artes da Universidade do Vale do Paraíba (UNIVAP). Email: lidiane@univap.br 
Trajetória de mobilidade e representações sociais:...

\begin{abstract}
This "essay-interview" is an experimental piece, co-produced by the authors who point out the same here. The proponent of the activity, Lidiane Maria Maciel, sociologist, invites the Young artist Inu Bere to reconstruct his mobility trajectory from East Timor to Brazil. On this occasion the artist questioned by the sociologist reconstructed the past of struggle for independence of his country through his family history. The interview is presented in a comprehensive manner, as Bourdieu (1997) in the work "The misery of the world". Space is given to a new performance of the reader, which must now be active in the search for the interpretation of the senses of what is exposed by the interviewee. The participation of the sociologist is made in the elaboration of the questions directed to the interviewee, and details when necessary to fill certain gaps so that the reader can expand his understanding, as well as in connection with other studies on the issue.
\end{abstract}

Keywords: Student mobility. Colonialism. Living space. Social representations. East Timor.

\title{
Trayectoria de movilidad y representaciones sociales de Timor-Leste a través de los recuerdos de Inu Bere
}

Resumen: Esta "entrevista de ensayo", es una pieza experimental, coproducida por los autores que señalan lo mismo aquí. La proponente de la actividad, Lidiane Maria Maciel, socióloga, invita a la joven artista visual Inu Bere a reconstruir su trayectoria de movilidad de Timor Oriental a Brasil. En esta ocasión el artista cuestionado por el sociólogo reconstruyó el pasado de lucha por la independencia de su país a través de su historia familiar. El espacio se da a una nueva actuación del lector, que ahora debe estar activa en la búsqueda de la interpretación de los sentidos de lo que expone el entrevistado. La participación del sociólogo se realiza en la elaboración de las preguntas dirigidas al entrevistado, y los detalles cuando es necesario para llenar ciertos vacíos para que el lector pueda ampliar su comprensión, así como en relación con otros estudios sobre el tema.

Palabras claves: Movilidad estudiantil, Colonialismo, Espacio vital, Representaciones sociales, Timor-Leste.

O Timor Leste é um país asiático cujo território abrange uma área de $14874 \mathrm{~km}^{2}$, ocupada por cerca de 1,1 milhão de habitantes. Para melhor entender as trajetórias de mobilidade desse país, é necessário levar em conta que os principais fluxos migratórios se direcionam para a Indonésia, Austrália, Reino Unido e Portugal. Em 2019, somava-se 39.202 mil timorenses fora do país, pouco mais de $3 \%$ de sua população. Este cenário é bem diferente 
daquele dos anos 2000, em que 16\% da população (148.339) estava fora, considerando o momento de perseguição vivido no país. No Brasil, em 2019, estimava-se que houvesse cerca de 66 timorenses. ${ }^{4}$

De todos os fluxos imigratórios que atravessaram o Brasil nos últimos anos, certamente, os vindos da Ásia, especialmente do Timor Leste, não são significativos numericamente, porém, podem ser lidos como representativos das estruturas sociais presentes na circulação global. Essas estruturas são compostas por resquícios coloniais, o fluxo de capital, ideologias, recomposição espacial/ territorial por agências internacionais como a Organização das Nações Unidas (ONU) e Organização Não Governamentais (ONGs), que marcam as vidas timorenses, com de Sinorino Bere de Jesus ou Inu Bere, como o artista ficou conhecido.

Figura 1: Mapa do Timor Leste - 2020

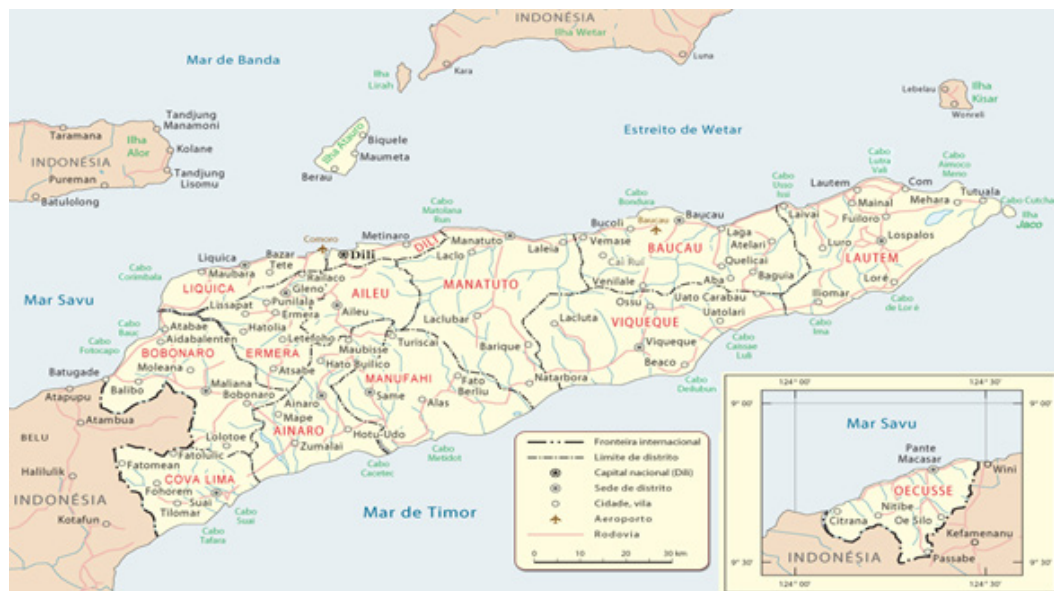

Fonte: Ásia-turismo (2020).

${ }^{4}$ Os dados de migração foram extraídos do site Country economy. Disponível em: https://pt.countryeconomy.com/demografia/migracao/emigracao/timorleste acesso em 30/04/2020. 
Inu Bere é artista visual nascido no Timor-Leste em 1997. Ele tinha apenas dois anos de idade quando foi realizada, em 1999, uma consulta popular sobre o destino de seu país, na época, um território ocupado pela Indonésia. Para conduzir o pleito, foi criada a Missão das Nações Unidas no Timor Leste (UNAMET) ${ }^{5}$, com a coordenação do brasileiro Sérgio Vieira de Mello. O anúncio do resultado da consulta constatou que quase oitenta por cento da população era pró-autonomia e independência em relação à Indonésia. Este fato provocou atos de violência e destruição nas comunidades de todo país. As ações eram promovidas pelas milícias pró-integração vinculadas à Indonésia. A família de Inu Bere não ficou ilesa nesse processo. Ele relata, nesta entrevista, vários fragmentos de memória do processo que foi contado pelos seus pais, da sua trajetória de vida e os anseios artísticos que constituiu desde muito novo.

[Lidiane Maciel] Inu, no Brasil, estudamos muito pouco sobre o Timor Leste. Apenas sabemos que as relações diplomáticas entre o Brasil e o Timor-Leste foram estabelecidas em 2002, ano da independência do país. Gostaria, então, de iniciar essa entrevista pedindo para que você nos contar um pouco do processo de independência de seu país, aquilo que você aprendeu com a sua mãe e seu pai ou com outros familiares.

[Inu Bere] bom, para falar do processo de independência de Timor-Leste, precisamos entender primeiro como (o país) chegou a este resultado. O Timor foi colônia dos portugueses por 500 anos. Eles chegaram em Timor em 1515 e saíram em 1974, quando aconteceu a Revolução dos Cravos em Portugal ${ }^{6}$.

5 Disponível em: http://www.eb.mil.br/unmit-timor-leste. Acesso em 30/04/2020.

${ }^{6}$ O Timor Leste continuou colônia de Portugal até a queda do regime de Salazar em 25 de abril de 1974. 
Figura 2: D. Boaventura de Soto Mayor, o Primeiro Rei Timorens

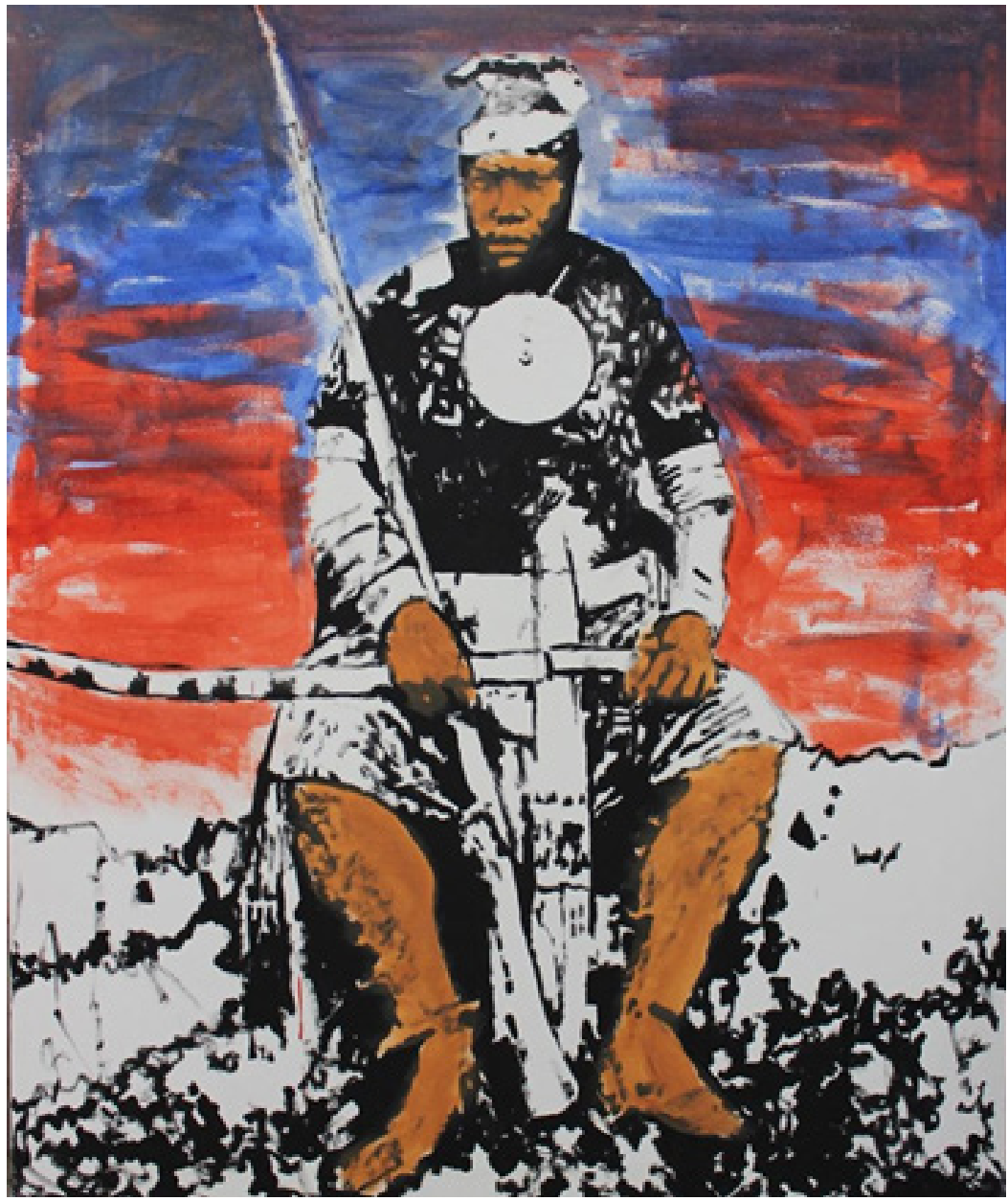

Fonte: Inu Bere. Acrílica sobre tela, Projeto Montanha, Aileu, Timor-Leste, parte da coleção "Nomes da Liberdade" (2016). 
Quando saíram os portugueses, eles deixaram o Timor livre para formar os partidos políticos. Surgiram, então, em 1974, os primeiros partidos do país, que eram: Associação Social Democrata Timorense ASDT - Frente Revolucionária do Timor Leste (FRETILIN); A União Democrática Timorense (UDT); Associação Popular Democrática Timorense (APODETI); e TRABALHISTA.

Por causa das diferenças ideológicas e políticas, os partidos conflitaram em si, por parte de UDT e FRETILIN. Alguns partidos queriam se filiar à Austrália, outros manter relação com Portugal, e UDT queria filiar-se à Indonésia, sendo FRETILIN o único partido que queria a independência total do Timor.

Com estas diferenças, em 1975, a UDT deu o primeiro golpe contra a FRETILIN e sofreu um contragolpe logo depois da FRETILIN, a qual conseguiu apoio popular. Em 28 de novembro de 1975, FRETILIN proclamou a independência do Timor unilateralmente, mas não obteve apoio dos outros partidos, nem de muitos países do mundo.

Menos de um mês depois, em 7 de dezembro de 1975, os indonésios invadiram o Timor. Uma das razões (da invasão) foi por medo de que o Timor se tornasse um país comunista. FRETILIN tinha o apoio das forças armadas de Timor, a FALINTIL, e então resistiu à presença dos indonésios durante 24 anos, de 1975-1999. De 1975-1978, FALINTIL era liderada pelo segundo presidente do país, Nicolau dos Reis Lobato. Sendo morto em combate, o sucessor foi Kay Rala Xanana Gusmão, até hoje o maior líder do país.

A partir dos anos 1980, com a liderança de Xanana Gusmão, a FRETILIN conseguiu expandir a luta do Timor, criando várias frentes e movimentos políticos, tanto dentro quanto fora do país, em prol da independência. Com Xanana Gusmão, criaram-se também as "Frente Clandestinas". (Esse) foi um movimento em que civis passaram a contribuir para a luta por meio da política, fazendo encontros escondidos, traçando planos para guerra, passando informações sobre as ações dos indonésios, ajudando os guerrilheiros com suprimentos, alimentos. As Frentes Clandestinas organizaram os povos da cidade para a independência. Cada uma delas possui código da luta. 
Figura 3: Xanana Gusmão

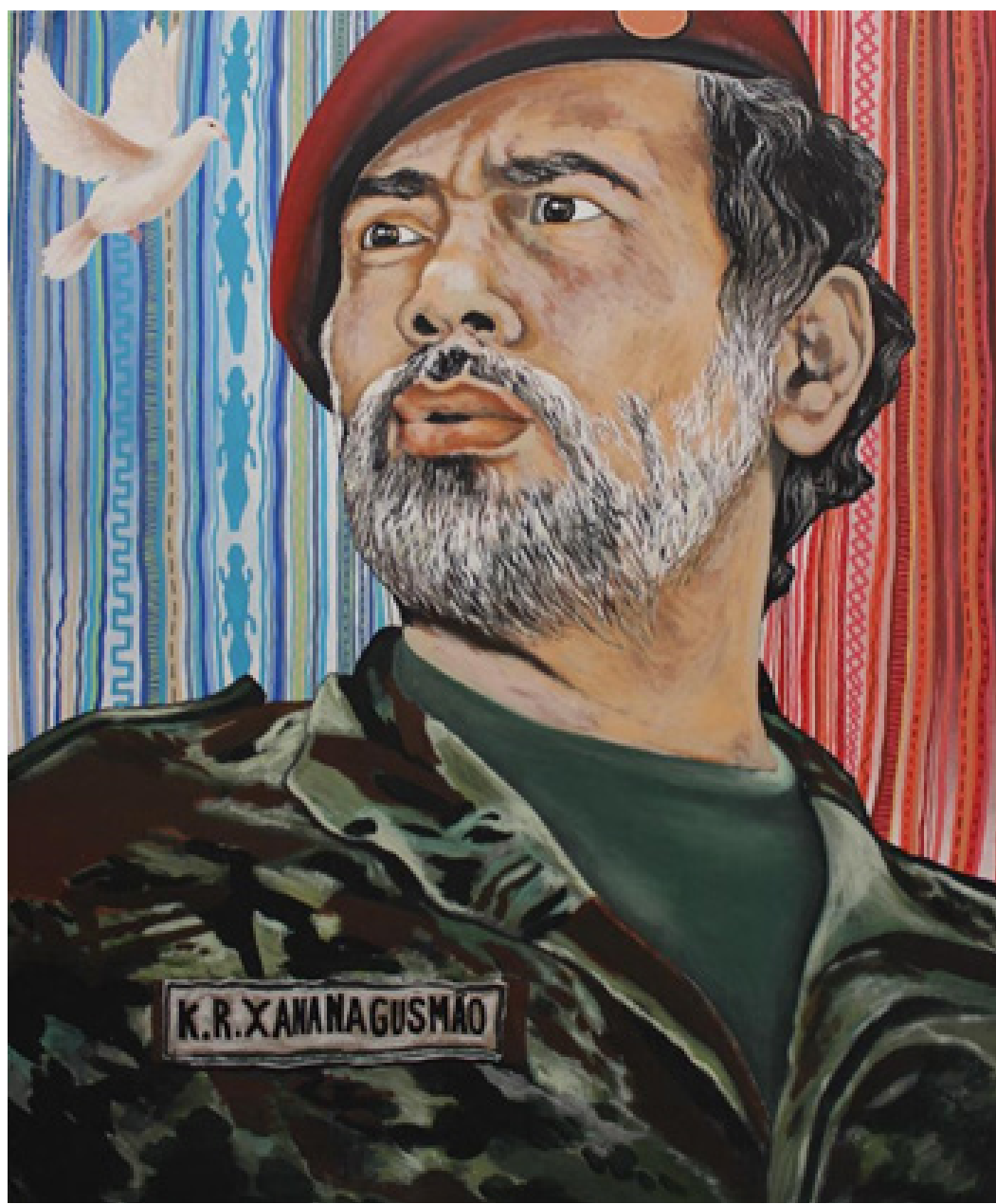

Fonte: Inu Bere. Acrílica sobre tela, Projeto Montanha, Aileu, Timor-Leste! Parte da Coleção Nomes da Liberdade (2016).

A luta de Timor constituiu-se em três Frentes: Armada, Diplomática e, por fim, Clandestina. Na liderança de Xanana Gusmão, conseguiu reestruturar o partido FRETILIN, e sua 
$|8|$

Trajetória de mobilidade e representações sociais:...

liderança também reconciliou e incluiu na luta os partidos que desde 1975 não queriam a independência, a liberdade do Timor. A figura de Xanana Gusmão logo ficou famosa no mundo, bem como figura de José Manuel Ramos, prêmio de Nobel da Paz junto com Bispo D. Carlos Filipe Ximenes Belo ${ }^{7}$.

Ramos Horta e Carlos Filipe Ximenes Belo, recebendo o prêmio Nobel da Paz em 1996 em Oslo, na Noruega, deram mais uma visibilidade para a luta do povo timorense. Neste caso, a Igreja Católica também teve um papel fundamental na luta de Timor.

A luta ganhou maior visibilidade ainda com o Massacre de Santa Cruz ${ }^{8}$, na capital Díli, em 12 de novembro de 1991. Muitos jovens foram massacrados, com isso a comunidade internacional, principalmente a ONU, começou a abrir os olhos para a luta de Timor. Ramos Horta e outros diplomatas timorenses também lutavam na ONU pela causa do Timor.

Em 1992, o Xanana Gusmão, líder da guerrilha timorense, foi capturado e colocado na prisão em Cipinang, Indonésio. A prisão do Xanana também causou um impacto para independência do país.

Em 1999, com a liberdade do Xanana Gusmão, a ONU propôs um referendo no Timor no dia 30 de agosto de 1999. Todo povo timorense foi votar e deveria escolher entre a integração à Indonésia ou a independência total, como país soberano.

Quase $80 \%$ dos timorenses votaram pela independência. Após o resultado, os indonésios não se conformaram e começaram a organizar os militantes contrários à independência do Timor. Eles foram convocados para causar conflitos, estupraram muitas mulheres, queimaram casas e escritórios, e muitos timorenses

\footnotetext{
7 Prêmio Nobel da Paz (1996) pelas ações em prol de "uma solução justa e pacífica para o conflito em Timor-Leste". Ver também: Ximenes Belo - Um prêmio Nobel Lusófono. Disponível em: https://pgl.gal/ximenes-belo-nobelpaz-lusofono/. Acesso em 05/05/2020.

${ }^{8}$ As tropas indonésias conseguiram matar 271 pessoas. Ver: disponível em: https://www.dn.pt/mundo/familiares-choram-massacre-de-santa-cruz-aindasem-corpos-para-enterrar-5493208.html. Acesso em 06/05/2020.
} 
foram forçados ao refúgio. Foi o momento em que o Timor foi queimado totalmente. Muitas pessoas morreram também, era um tempo de caos no Timor. Em 20 de setembro de 1999, as tropas de paz da Força Internacional para Timor-Leste (InterFET), liderada pela Austrália, foram implantadas no país, o que pacificou a situação rapidamente. O representante especial da ONU era Sérgio Vieira de Mello, o brasileiro que ainda é muito querido no Timor.

Durante os anos de 1999-2002, Sergio ajudou a transferir o poder para os timorenses a partir das eleições presidenciais e legislativas, bem como ajudou a administrar o país durante este período. Então, em 20 de maio de 2002, o Timor-Leste restaurou novamente sua independência, sendo Xanana Gusmão eleito como o primeiro presidente do país independente. Foi um dia memorável e comemorativo.

Nós moramos em Aileu, um estado no interior de Timor, a $42 \mathrm{~km}$ de capital, Dili. Em 1998, meus pais construíram nossa nova casa. Eles tinham acabado de terminar, em 1999, quando sofremos um atentado e a casa pegou fogo, todos os pertences foram queimados. Salvamos apenas alguns documentos importantes.

A partir dos anos 1990, meus pais se formaram e se tornaram professores, porém o principal trabalho era servir como informantes de FALINTIL na cidade, ou lugares onde estavam os exércitos indonésios, pois FALINTIL, na sua maioria, ficava no mato $^{9}$ (montanhas) de Timor e não podia estar em todos os lugares, principalmente lugares mais expostos, como as capitais e cidades. Quando o comandante de guerrilha queria estar na cidade, era sempre um estafeta ou pessoal da frente clandestina que ajudava a se disfarçar para que pudesse estar na cidade a tratar dos assuntos da guerra. O código da luta da minha mãe era CAINONIA e do meu pai era AIRUSMERA, o código mais famoso. Como meu pai fazia parte da liderança da política da nossa região, chamado "20 de agosto", ele foi perseguido também. Além disso, ele tinha outros códigos da luta, pelo que minha mãe contou, pois dependia

\footnotetext{
${ }^{9}$ Mato é um termo que usamos muito no Timor para designar um conjunto de montanha e florestas junto com cavernas.
} 
do serviço. Cada serviço tinha códigos diferentes. O último código que conhecemos também foi MAUBISSE 2, do serviço secreto militar FALINTIL, até o seu falecimento em novembro de 2013.

Desde sua infância, meu pai já se envolvia com meus avós na luta. Meu avô era delegado de FRETILIN da nossa cidade. Ainda criança, meu pai ajudava os meus avós a alimentar as forças armadas de Timor, a FALINTIL, pela luta de libertação. (Ele) trabalhava no campo de arroz, na horta para poder alimentar os guerrilheiros.

Na juventude de meu pai, (ele) fazia parte de vários grupos políticos para a independência. Ele também foi preso e torturado algumas vezes por defender a independência de Timor e por passar informações sobre situações da cidade para os guerrilheiros de FALINTIL. Meu pai era da Frente Clandestina, e a maioria dos trabalhos de Frente Clandestina era lutar por meio da política nos lugares onde os guerrilheiros das FALINTIL não podiam estar, pois a guerrilha com armas acontecia no mato, mas a guerrilha com a política acontecia na cidade através da Frente Clandestina. Estes guerrilheiros da Frente Clandestina, na sua maioria, eram estudantes, profissionais e funcionários públicos, professores, mulheres, até mesmo jovens de menores idades.

[Lidiane Maciel] como era a trajetória da sua mãe? Como ela atuava na resistência?

[Inu Bere] de ano 1992-1999, minha mãe foi chefe de OMT (OrganizaçãoMulher de Timor) danossa divisãoterritorial chamada de Laun Tulalaun (aqui mais ou menos como um município). Desde criança até sua juventude, minha mãe servia aos guerrilheiros no mato distribuindo alimentos. O nome do grupo dela era Ransu. Ela contribuía diretamente para os "estafetas" responsáveis por levar cartas e alimentos/suprimentos para os guerrilheiros.

Nesse período, minha mãe também andava com padres e freiras da Igreja Católica fazendo pastorais nas aldeias. a Igreja Católica contribuía divulgando informações para a população sobre a luta do Timor, de maneira a encorajá-los para a independência. 
Minha mãe também contribuía por meio do meu pai, pois ela assegurava seus segredos, cuidava dele. $\mathrm{O}$ que minha mãe dizia era que meu pai ainda guardava muitos segredos e não contava tudo para ela para nos proteger.

Minha mãe também contou que ela estudou no "mato", que na escola não tinha giz e caneta, elas escreviam usando carvão e pedra colorida. Usava até mesmo folha de bambu ou de banana. A escola era embaixo de uma barraca, os estudantes se sentavam no chão ou na cadeira de bambu. Certa vez, teve um atentado (bombardeio) no local e a explosão acertou várias pessoas, inclusive minha mãe, que se feriu nas costas.

O pai da minha mãe era chefe de aldeia (aqui mais ou menos um líder de bairro), uma figura muito influente na família, e era delegado da FRETILIN. Os outros dois irmãos da minha mãe eram guerrilheiros da FALINTIL.

Figura 4: Inu Bere no Atelier UNIVAP, São José dos Campos, Brasil - 2019.

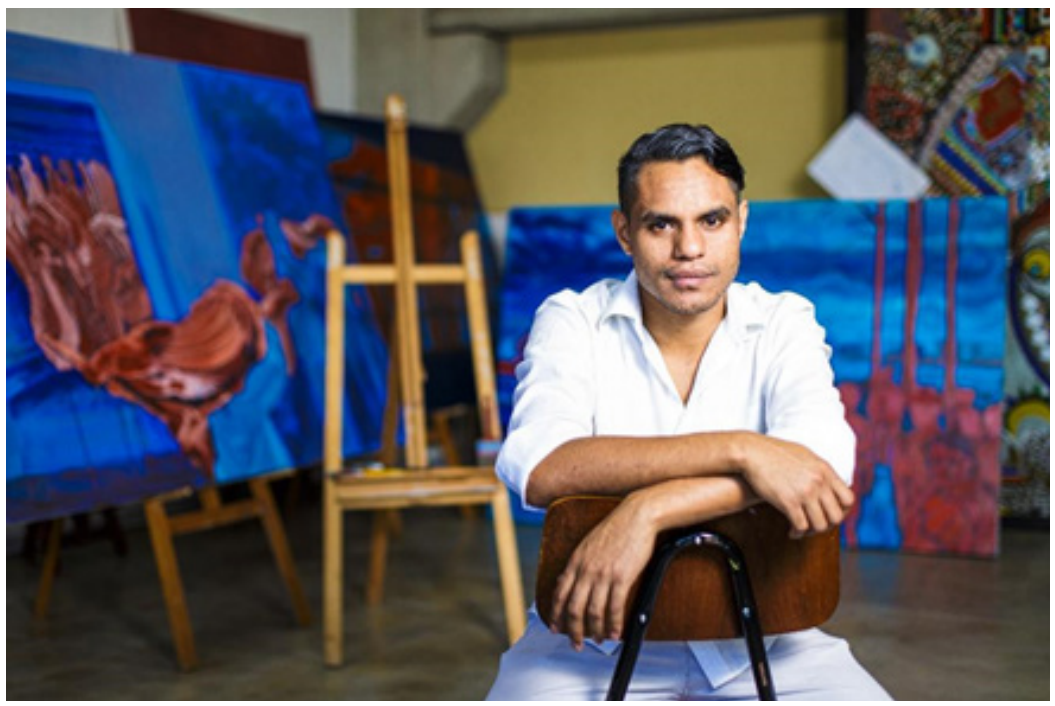

Fonte: Alberto Rocha - projeto O Circulador. 
Em 14 de setembro de 1999, por causa do conflito causado pelos grupos de milícias, eu, minha mãe grávida do meu segundo irmão e meus tios fomos obrigados a sair do país e nos refugiar do lado indonésio. Meu pai teve que ficar e resistir. Esta foi primeira vez que sai do meu país, no cheiro do queimo e caos do conflito da guerra. Tinha apenas dois anos de idade.

Com as intervenções das forças do INTERFET, um mês depois, no dia 30 de outubro de 1999, voltamos para Timor para encontrar toda a família e novamente meu pai. Fomos recebidos pelas Nações Unidas ACNUR (Alto Comissariado das Nações Unidas para os Refugiados) e Cruz Vermelha.

As forças milícias ameaçavam os timorenses e exigiam a saída de todos. Muitos militares indonésios ingressaram na guerra, e isso pressionou os timorenses a fugir para o lado indonésio. Minha mãe também conta que eles queriam o povo lá para que pudessem realizar uma outra eleição, porque não aceitavam as eleições em Timor. Por isso, os timorenses foram para a Indonésia em 1999 pressionados e levados por milícias. Mas este plano das milícias não deu certo porque o Timor já estabelecia redes de comunicações que favoreciam a independência. Naquela altura, (a independência) já havia sido declarada na ONU e o Xanana Gusmão já tinha sido libertado da prisão.

Como toda família que esteve em época da guerra e que, na sua maioria, perdeu familiares, familiares dos meus pais também (foram perdidos). A família da minha mãe, tanto como a do meu pai, também perdeu familiares. Tios, irmãos e filhos dos irmãos da minha mãe, por causa da fome, muitos morreram. Meus pais vivenciaram momentos mais críticos pela guerra, como matança, corpos espalhados pelo "mato", fome, sem saber para onde ir. Os indonésios invadiram o Timor com aviões, bombardeiros, tanques de guerra e navios que bombardearam e acabaram com o "mato" timorense. Ou o povo se rendia ou morreria pela guerra e fome. Sendo que o exército timorense tinha apenas armas, e armas do antigo militar português, a partir do ano 1980 uma das estratégias de Xanana Gusmão foi incluir os civis na cidade para luta também. $\mathrm{E}$ as forças ficaram nas montanhas ou territórios mais escondidos 
do interior para guerrilha. Por isso, muitos timorenses civis que não tinham fugido para o mato (montanhas, selvas, cavernas onde tinha mais possibilidade de se abrigar) contribuíram também para a independência. Os anos de 1975 até 1980 foram uma das épocas mais terríveis de guerra.

Meu pai contou também que muitas mulheres foram estupradas e violentadas sexualmente. Muitos dos indonésios queimavam o cigarro no corpo delas após as violarem. Havia também esfaqueamento e todo tipo de violência que se possa imaginar. Os indonésios mandavam muitos prisioneiros até mesmo comer fezes, maltratavam-nos e não lhes davam comida. Além de sofrimento físico, era o sofrimento psicológico, e isso deixa marcas em muitos timorenses até hoje. Como diz a palavra do nosso comandante Xanana Gusmão: "os indonésios não apenas destruíram o Timor, mas roubaram-lhe a alma do povo timorense".

[Lidiane Maciel] como são as relações com os brasileiros que vivem ou viveram no Timor, incluindo a figura de Sérgio Vieira de Mello?

[Inu Bere] a maioria dos brasileiros que conheço no Timor são missionários evangélicos, da Igreja Batista, Presbíteros, Cristão Visão, Assembleia de Deus, que trabalham em maioria com a educação, escolas, organizações não governamentais que trabalham com adolescentes ou mulheres que sofrem violência sexual, e alguns trabalham para o governo. Também há outros brasileiros que trabalham com jornalismo. Todos eles, de alguma forma, contribuem para o processo de construção do país.

Minha relação, mesmo, com os brasileiros é com meus diretores de Projeto Montanha ${ }^{10}$. Eles são missionários também e já moravam em Timor há 10 anos. Foi por meio deles que construímos o Projeto Montanha, com o intuito de suportar e treinar jovens

\footnotetext{
${ }^{10}$ Sobreprojetocitadover:Futuros Criativosem Timor-Leste, oprojetoMontanha disponível em: https://www.youtube.com/watch?v=LBuzsQZ2YwQ. Acesso $30 / 04 / 2020$
} 
timorenses em diversas áreas do conhecimento, incluindo arte, da qual sou líder.

Sérgio Vieira de Mello é uma figura muito querida em Timor. Nós, timorenses, reconhecemos muito este brasileiro que tanto contribuiu para o processo de recomeço do nosso país. Em Timor, Sérgio dá nome a um dos prêmios de Direitos Humanos. Em Timor, o Estado busca sempre valorizar pessoas que lutam e trabalham para Direitos Humanos, e o prêmio leva o nome dele, Prêmio de Direitos Humanos Sérgio Vieira de Mello.

Sérgio foi um grande idealista e teve um papel importante nos primeiros tempos de um novo Timor: ele foi o administrador do país durante 1999-2002 e ajudou a implantar as instituições, uma constituição redigida pelos timorenses, a formar lideranças locais, a organizar duas eleições, uma presidencial e uma legislativa, a administração pública, um Banco Central, o Órgão fiscal, as instituições de defesa. Sérgio também defendeu a igualdade de gênero em todos os processos de construção de Timor-Leste.

Tenho um apreço muito grande por certos brasileiros, e Sérgio Vieira de Mello é um deles. (Outros são:) Ayrton Senna, Sebastião Salgado, Vik Muniz, Pelé, e tantos outros que embelezam o mundo com suas personalidades e contribuições para humanidade, que inspiram muitos e com quem que aprendemos também. Quero dizer que, nestes tempos de hoje, podemos aprender com estas figuras, principalmente os brasileiros, sabendo que este belo país também tem pessoas peculiares que fazem a diferença.

[Lidiane Maciel] como é o ensino da língua portuguesa no Timor? Há outras línguas/dialetos?

[Inu Bere] eu diria que ainda muita coisa precisa ser feita do ponto de vista sobre o currículo, até mesmo os professores precisam de mais informações, ou professores da área mesmo, pois a maioria deles consegue se comunicar um pouco e aprendem a língua por conta própria. Nós ainda não temos professores em várias especialidades do conhecimento, o que também acontece com a língua portuguesa. Hoje, o governo timorense está investindo 
(na educação), mas também na formação dos professores de língua portuguesa, e acredito que daqui a alguns anos (o número de professores) vai crescer muito. Mas, pelo menos há seis anos, quando eu estava no Ensino Médio, os professores passavam gramática, pediam para decorar os verbos, e os alunos muitas vezes copiavam os vários textos, tentando estudar ou decorar para falar.

Pois até mesmo os professores que davam aula de português não conseguiam se comunicar. Também entendo que português é uma língua muito difícil. Porém, nós temos já algumas instituições como Cooperação Portuguesa, Cooperação Brasileira, Fundação Oriente, GASPORTO, Projeto Montanha, SENAI, LABEH (lalenok ba ema hotu), LELI, UNTL (Universidade Nacional Timor Lorosa'e), Instituto Camões, ABUT Timor, Fundação Renovar, além de outras pequenas organizações que não conheço muito bem, que trabalham com esta língua na formação dos jovens e estudantes.

Hoje, o governo timorense tem parceria com o governo de Portugal para administrar a escola de CAFE (Centro Aprendizagem Formação Escolar), uma escola liderada por timorenses e portugueses que existe em todos os estados do país, desde o Ensino Fundamental até o Ensino Médio. Lá, todo o ensino é de português, e é uma escola muito boa. Meu irmão caçula estuda nesta escola.

Nós temos também a Escola Portuguesa de Ruy Cinatti, na capital Díli, que considero a melhor no ensino de português e outras áreas também, desde o Ensino Fundamental até o Ensino Médio. Meu segundo irmão estuda lá. Tanto meu segundo irmão como o meu irmão caçula falam bem português e nos comunicamos em português também.

E no Projeto Montanha, a organização da qual sou um dos líderes, nós trabalhamos muito na formação dos jovens e estudantes principalmente na língua portuguesa. É onde eu aprendo português e é a organização da qual meus dois irmãos e eu fazemos parte como equipe de liderança. 
$|16|$

Trajetória de mobilidade e representações sociais:...

Antes de os indonésios entrarem, o Timor tinha por volta de 32 línguas nativas, ou dialetos. Hoje permanecem poucas. Eu diria que, talvez, apenas 19 línguas nativas permanecem, e aos poucos elas estão desaparecendo, porque as novas gerações não falam mais, ou não aprendem. Elas falam Tétum, que é a língua mais falada do país. Dez por cento da população falam português, alguns falam também inglês e bahasa do Indonésio. Eu sei falar a língua do meu estado, que é Mambaí. Também falo Tétum, português e inglês. Hoje a língua falada, ou a língua do país mesmo, é Tétum. Português e Tétum são consideradas como línguas oficiais do país.

\section{[Lidiane Maciel] qual origem do Tétum?}

[Inu Bere] não consigo explicar de uma maneira teórica, mas lembro que quando eu estudava no ensino fundamental uma das disciplinas era língua Tétum, e, pelo que o professor explicou, antes de os portugueses entrarem em Timor-Leste, tinha vários dialetos no país, cada clã tinha suas próprias línguas. Tinha também o Tetum Terik, de onde se originou a maior parte do Tétum de hoje.

Porém, quando os portugueses entraram, para conseguir uma maneira de comunicação geral com todo o povo timorense, então nasceu o Tétum Praça, Tétum que hoje em dia toda a população fala. Portanto, a origem de Tétum, primeiro, vem de Tétum Terik e, depois, a ortografia de Tétum vem do português. Nós temos muitas palavras que não temos em Tétum. Por exemplo, lápis é lápis, mesa é mesa. As primeiras escritas da ortografia de Tétum foram feitas pelos padres jesuítas da missão da Igreja Católica em Timor-Leste. Alguns anos atrás, foi desenvolvido também um instituto ligado a UNTL (Universidade Nacional Timor Lorosa'e) com o foco no estudo sobre o desenvolvimento de língua Tétum, o INL (Instituto Nacional de Linguística).

[Lidiane Maciel] como é a questão religiosa no Timor? A presença das igrejas é bem vista e aceita?

[Inu Bere] o povo timorense na sua maioria tem sua própria crença. Antes mesmo de os portugueses entrarem no Timor, havia 
a adoração de elementos da natureza, pedras, madeiras, fogo, faziam-se sacrifícios com animais. Eu diria que era uma religião com bases no animismo. Hoje, isso se misturou ou casou-se com a religião Católica Romana. Além disso, estas crenças são ligadas à Casa Sagrada Uma Lulik. Toda família timorense tem uma. (É) uma casa onde, em períodos ou estações do ano, ou dependendo de certos assuntos para ser tratados, muitas famílias se reúnem para realizarem várias cerimônias rituais tradicionais. É uma maneira de talvez buscar alguma ligação. Eu diria, é uma religião também. É tudo que posso falar sobre (o assunto), pois já nasci numa família em que nós não temos muito contato com estas crenças, então acabei não sabendo muito sobre este lado de Timor. Sei que tem muita coisa e é um assunto complexo que causa curiosidade em muitos antropólogos e sociólogos no mundo sobre o Timor.

O Timor-Leste é um país de Estado laico, temos liberdade de crenças e cultos religiosos, embora $90 \%$ da população seja Católica Romana, 6\% (membro) do Islamismo e 4\% dos Evangélicos ou Protestantes. Particularmente, digo que é aceito, se a lei permite a liberdade da religião, é a isso que devemos nos atentar, e respeitar a crença dos outros.

[Lidiane Maciel] como é a relação com Portugal? E com a Indonésia? Há muitos emigrantes timorenses lá, não é?

[Inu Bere] hoje, a relação com Portugal e Indonésia é muito boa. Desde a luta pela independência de Timor, o povo português apoiava muito. Embora muitos não se pronunciassem, tinham um carinho especial para Timor. Primeiro, pelo fato histórico de que foi considerado um pedaço de Portugal e, segundo, pelo fato político e cultural de que a língua portuguesa nos une. Durante a luta, muitos portugueses apoiavam o Timor, choravam por Timor, e hoje Portugal é um país irmão também.

A Indonésia, hoje, é um país irmão também, e a nossa relação é muito boa. Consumimos a maioria dos produtos da Indonésia, pois o Timor não tem ainda grandes fábricas/indústrias e grandes escalas de produção, então maioria dos produtos vem 
da Indonésia. Após a independência, o primeiro presidente do país, Xanana Gusmão, decidiu perdoar os indonésios. Este foi um ato extraordinário que estabeleceu uma ligação especial entre timorenses e indonésios. Hoje acredito que ainda haja muitas marcas da guerra, mas não há nenhum timorense que conheço que tenha ódio dos indonésios. Aprendemos que o passado deve ser contado como fato histórico para que aprendamos a olhar para o futuro. O ódio não leva a lugar nenhum, a não ser em vão, (pois) quem tem ódio fecha o caminho das oportunidades para si mesmo, é amargurado, nunca será satisfeito e nunca será feliz. Perdoar significa que agora vivemos uma vida nova.

[Lidiane Maciel] há uma comunidade de migrantes de Timor-Leste no Brasil? Você conhece outras pessoas de seu país aqui?

[Inu Bere] sei que tem alguns que estudam no Norte, dos quais três eu conheço, e alguns estudam no Sul, mas não tenho um contato fixo com eles. Eles vêm por meio da bolsa cedida pelo governo. No meu caso, vim pela bolsa da minha organização, o Projeto Montanha.

Pelo que sei, no estado de São Paulo, ou a cidade de São José dos Campos, sou o único timorense que mora e estuda aqui.

[Lidiane Maciel] como foi seu processo migratório? Quais as etapas até aqui?

[Inu Bere] quando entrei no Projeto Montanha pela primeira vez em 2013, estávamos começando a construir o projeto. Um dos seus objetivos era formar novos líderes timorenses em todas as frentes do conhecimento para tocá-lo futuramente. Eu sou o primeiro jovem a ganhar a oportunidade para estudar arte e voltar liderar o departamento de Arte do Projeto Montanha. Estou à frente de um projeto de montar um Instituto de Arte, uma galeria e um museu no nosso estado, será o primeiro instituto do país. 
Logo que entrei, começamos a pensar sobre meu futuro, onde eu estudaria. Além de pensarmos em outros países, o Brasil se apresentou como uma grande possibilidade porque meus diretores da família Trucco são brasileiros, e isso facilitou muito para que eu estudasse aqui. Depois comecei a aprender falar português todos os dias dentro do Projeto Montanha. Minha coordenadora, Gisele Trucco, dava aula de português, e foi assim que aprendi o idioma.

A Família Trucco, eles são missionários da primeira Igreja Batista de Pouso Alegre e chegaram em 2009 pela primeira vez em Timor. Era uma família com dois adolescentes. Os dois filhos deles estudaram e terminaram o ensino médio da mesma escola em que eu estudei. Os primeiros trabalhos deles construíram fogões mineiros em vários estados do país com o objetivo de diminuir a destruição do meio ambiente. O corte da lenha é muito significativo em Timor, porque as pessoas cozinham em três pedras com muita lenha e fumaça. Eles também davam aulas de nutrição, pois ainda hoje o Timor tem muito problema de má nutrição, e davam aulas de português. Em 2012, construíram o Projeto Montanha e hoje eles lideram esse projeto junto conosco, os timorenses. É uma ONG não governamental e não denominacional. Trata-se de uma organização cristã independente, com o foco do trabalho na educação e formação de jovens timorenses, principalmente do estado de Aileu. Hoje, o Projeto Montanha é muito bem aceito no país e, principalmente, na comunidade de Aileu.

Quando terminei o ensino médio em 2015, pensávamos que eu precisaria de mais um ano para ter experiência na capital, trabalhar um pouco mais na minha arte e estudar um pouco inglês também. Em 2016, então, fiz um curso de inglês na capital, realizei uma grande exposição de retrospectiva e me preparei mais emocionalmente para encarar uma nova realidade. Durante este período, meus diretores estavam estabelecendo uma parceria com a Universidade do Vale do Paraíba (UNIVAP) para eu pudesse estudar em São José dos Campos.

Em 2017, como parte do requisito exigido pela UNIVAP, eu precisaria cursar uma faculdade em um período para que pudesse pedir a transferências. e então, nos seis primeiros meses de 2017 
fiz faculdade de Agropecuária na Universidade Nacional de Timor Lorosa' e, depois, me transferi para a UNIVAP. Na UNIVAP, entrei logo no quinto período, porque não tinha formado uma turma nova, então segui as aulas com a turma de artes de 2016.

[Lidiane Maciel] quando saiu do Timor? Qual percurso fez? Veio direto para o estado de São Paulo? Teve algum apoio institucional?

[Inu Bere] saí do Timor em julho de 2017. O diretor do Projeto Montanha, Eduardo Trucco, me acompanhou durante a viagem, pois nunca tinha feito nenhuma viagem internacional longa. Passamos primeiro por Bali, Kuala Lumpur e Amsterdam, na Holanda. Ficamos dois dias em Amsterdam visitando museus. Depois de Amsterdam, Guarulhos/São Paulo, e logo vim para São José dos Campos. Depois de dois dias, já estava na faculdade.

\section{[Lidiane Maciel] há quanto tempo está no Brasil? Como chegou a São José dos Campos? Veio com familiares e parentes?}

[Inu Bere] eu estou no Brasil há quase três anos, vim direto para a cidade, e não vim com a família, apenas eu mesmo.

[Lidiane Maciel] como se sente morando em São José dos Campos/SP? Quais as principais dificuldades encaradas no dia a dia? Como foi a acolhida?

[Inu Bere] morar numa cidade como São José dos Campos é uma realidade nova para mim, pois a diferença é muito grande em termos de infraestrutura, modo de vida, meios de transporte, até mesmo a maneira como as pessoas se comunicam.

Meu estado natal possui por volta de 50.000 habitantes, minha cidade, posso dizer, 10.000 habitantes. O Timor, como ainda, é um país novo não temos tanta burocracia em relação a serviço público, os meios de transportes também são poucos e o trânsito é calmo, quase todos se conhecem, todos no meu estado, 
ainda mais na minha cidade. A primeira vez que cheguei aqui, tive que aprender e me adaptar a tudo. A língua foi minha primeira dificuldade, depois tive que aprender a seguir os protocolos dos serviços públicos, tive que aprender a me adaptar ao transporte público. No meu país, só temos taxi, caminhão e Mikrolet (parecido com uma van de transporte, mas ainda diferente). Aqui tive que aprender a andar de ônibus, me adaptar ao apartamento e, até mesmo, ao modo de me comunicar com as pessoas. Sim, demorei um pouco para me adaptar.

Posso dizer que, junto com a faculdade e outras atividades que faço, o dia a dia parece agitado, até mesmo as pessoas parecem agitadas, principalmente no trânsito. Sempre busco me comunicar melhor todos os dias, sempre busco ter mais uma noção sobre a cidade todo dia, sempre busco aprender a apreciar a cidade como ela é, não como do jeito que crio nas minhas ilusões.

Depois de dois anos morando em São José dos campos, (a cidade) me parece cativante, gosto muito da mistura que a paisagem joseense oferece, a urbanidade com a paisagem natural, onde podemos ter contato com natureza como Banhado ou a Urbanova, ao mesmo tempo estar dentro da cidade, como no Aquárius ou no centro como Calçadão. De vez em quando faço o exercício de andar pela cidade de manhã cedo para ver seu vazio e apreciá-lo. São José também oferece um belo pôr do sol, que tem o cheiro das lembranças da minha infância, e oferece uma manhã banhada por orvalhos que remetem ao meu país também. Na noite, (a cidade) é linda. Aprecio muito a noite na cidade grande, me faz sentir que toda noite é Natal. Talvez as luzes dos prédios façam o lugar das estrelas. Gosto das luzes da cidade à noite.

Sou muito acolhido aqui, principalmente na faculdade, sou bem acolhido pelos professores e alunos da UNIVAP, e tenho amigos e professores que ficarão sempre no meu coração. Também sou bem acolhido pela população da cidade, pelas pessoas que conheço. Participo de vários eventos de artes, faço parte do grupo de Atelier de gravura De Etser em Santana, no qual sou bem acolhido pelos amigos artistas, gravadores e pintores. Por conta de ser um estrangeiro, isso causa uma certa curiosidade nas pessoas. 
[Lidiane Maciel] você tem contato com seu país? Voltou para lá alguma vez nos últimos anos?

[Inu Bere] tenho contato através das redes sociais, acompanho as notícias do meu país, também falo com minha mãe e meus dois irmãos e meus amigos do Projeto Montanha, que é como minha segunda família também. Voltei para Timor em dezembro de 2018, passei o Natal lá com minha família e o Projeto Montanha.

[Lidiane Maciel] quando você voltou, como se sentiu? Quando comparou o país que havia deixado?

[Inu Bere] acredito que o homem é um ser que se adapta, e, à medida que ele se adapta, sua adaptação o transforma também. Penso que nós somos transformados ou mudados por três pontos importantes: a cultura (onde entram todos os tipos de conhecimento, a língua, o modo de falar, a comida, etc.); o espaço (onde entram a localização e a mobilização de um lugar para outro, Timor-Brasil); e o tempo (a duração de todas as coisas, sentimentos e paixões, momentos ou ciclos de vida).

Algo muito importante que notei foi como eu tenho muita vontade e curiosidade de conhecer o mundo. Outras pessoas também têm muita vontade e curiosidade de conhecer o Timor, e isso me faz pensar, refletir e estudar mais sobre meu próprio país. Nós devemos estudar outros países, buscar outras culturas, mas devemos primeiro conhecer a nossa própria cultura. Depois de sair e voltar, vejo muito mais possibilidades, pois abriu minha mente de que é possível construir algo que antes eu não acreditava que podia ser em Timor. É possível sonhar!

Algo marcante também é que esse foi meu primeiro contato de verdade com o mundo, onde eu precisava me adaptar, aprender e acreditar. Isso me permitiu criar uma nova identidade minha e, ao mesmo tempo, pensar que tudo não acontece de um dia para outro como sonhamos. Devemos sonhar, sim, junto com isso trabalhar muito, lutar muito, aprender a ter paciência e que tudo acontece em seu devido tempo. 
[Lidiane Maciel] como é ser artista no Timor? E no Brasil? Quais as proximidades e diferenças?

[Inu Bere] entendo que, como um país novo, mesmo já fazendo quase 19 anos de independência, o país (Timor) está ainda na fase de construção do desenvolvimento. Há muitas áreas para serem desenvolvidas, como saúde, educação, água e saneamento, nutrição, habitação de comunidade, planejamento urbano. e então, o campo das artes vem no último plano mesmo, muito embora o Ministério de Arte e Cultura de Timor, junto com o Ministério de Turismo, tem promovido eventos culturais e artísticos ao longo dos anos. Na maioria dos casos, os principais eventos são de concerto de música, competição de danças tradicionais, poesias, teatros, e um pouco na pintura. Mas o que estou querendo dizer é que o campo da cultura e das artes vai além destes eventos e linguagens. Quando falamos da arte e cultura, tem a ver também com a educação, e defendo que arte e cultura devem ser ensinadas também dentro do currículo da educação timorense de uma forma profunda.

Então, ser artista em um país considerado subdesenvolvido, onde a necessidade básica é de alimentação para sobrevivência e ainda existem várias lacunas a serem preenchidas - não é fácil-, (a arte) é quase um ato de resistência, e ainda o artista precisa convencer as pessoas ao seu redor de que é algo importante. $\mathrm{O}$ mercado das artes no Timor é pequeno ou é quase nulo, os artistas na sua maioria trabalham para sobreviver, mas não para criar uma carreira ou expandir mais seu campo para outras áreas. Nós não temos ainda uma Escola de Arte que engloba todas as áreas e linguagens.

Sonhar em ser artista no Timor, então, é algo fora do comum e que talvez não entre na cabeça de muitos, até mesmo familiares. Desde cedo sempre gostei da arte. Até hoje, um dos motivos de eu estar aqui no Brasil é a minha arte. Desde o ano de 2012 até agora busco sempre construir minha carreira, construir relacionamentos, conhecer vários campos da arte e, até mesmo, construir uma autoridade para que eu possa ser um exemplo e mostrar que é possível, que a arte e a cultura são importantes também. 
Hoje em dia, muitos declaram que a arte não tem nenhum compromisso social, (que a) arte é para apreciar, arte é apenas arte. Para mim, nada é separado, tudo está ligado, e a arte é um campo que está ligado com todas as áreas. Ela também é um ato de política, um ato de resistência, um ato social, ou ela pode ser apenas arte. No meu caso, gosto de trabalhar a arte junto com o compromisso social: de toda a venda das minhas obras, metade vai para os jovens do Projeto Montanha, para ajudar e participar na educação desses jovens.

Também trabalho com arte-educação. Acredito que esse é um dos meios para contribuir com a formação do ser humano, e defendo a arte no geral, não só pintura ou gravura, mas a arte em todas as suas dimensões. Uma arte para todos, não só para um certo grupo.

Sei que pode parecer pouco para os joseenses, mas a arte joseense já tem um avanço muito significativo. Tem várias instituições que trabalham com isso: tem a Fundação Cultural Cassiano Ricardo (FCCR) que abrange bastantes campos, tem galerias, museus, e já tem profissionais de artes, arte-educadores, curadores, artistas, um circuito que já está bem formado. É uma cidade que considero cultural também. Na minha cidade natal não tem nenhum museu ou galeria, e o Projeto Montanha é a única instituição que toma a frente disso no meu estado e está sendo um dos pontos turísticos para o país.

[Lidiane Maciel] conte-nos um pouco sobre sua arte? Quais suas percepções? O que tem produzido? Onde já fez exposições?

[Inu Bere] meu trabalho tem mais ou menos três dimensões principais. Além de várias interpretações e significados, uma obra de arte nunca tem só um significado. Primeira dimensão é a dimensão artística e plástica, o trabalho em si. A segunda dimensão é a dimensão política e filosófica. Aqui falo da questão da cultura, política, social. Trato também do meio ambiente e busco sempre falar dos temas da atualidade, do cotidiano. E a última dimensão é a dimensão espiritual, na qual busco a espiritualidade da arte, 
trato das emoções e sentimentos, a tranquilidade e paz, o belo e o encontro com o Divino. Esta é a parte mais essencial para mim.

Nestes últimos dois anos, tenho focado numa pesquisa de Azul e Vermelho, uma série que estou desenvolvendo desde o ano de 2018 na UNIVAP. Trata-se da paisagem brasileira, principalmente a joseense e a Serra de Mantiqueira, pois são lugares que percorro neste momento. Uma série de 100 pinturas de grande dimensão, 130 por $200 \mathrm{~cm}$. Trata-se de uma pesquisa também sobre a linguagem, a pintura, por meio da qual estou buscando um novo nível de qualidade plástica e profundidade do impacto no espectador.

Figura 5: Neblina do banhado cinco da manhã São José dos Campos.

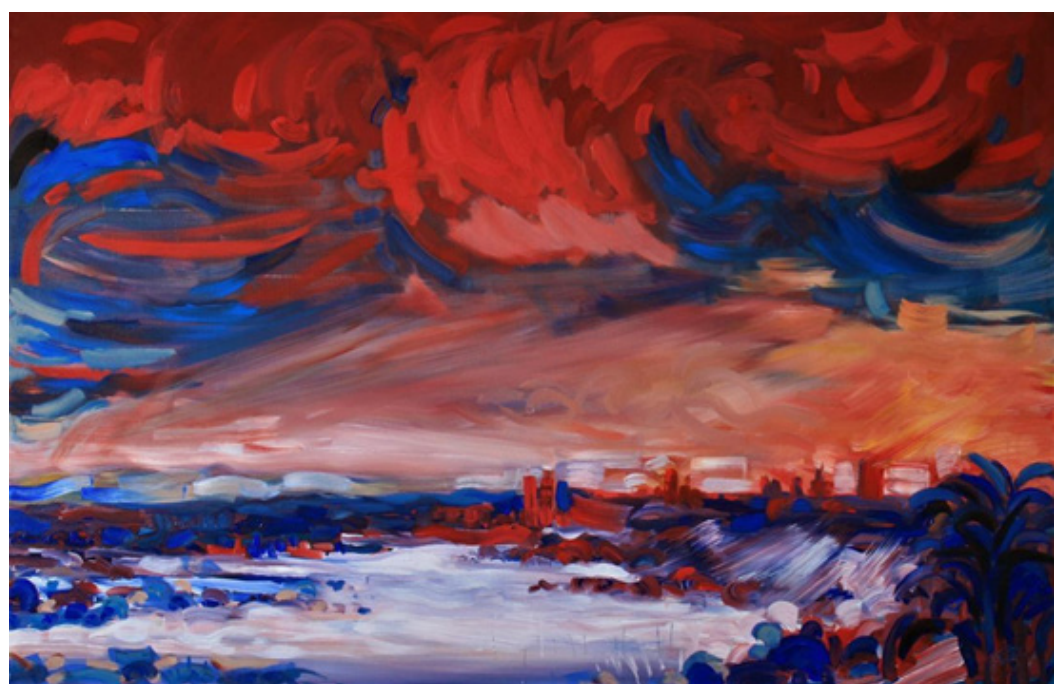

Fonte: Inu Bere. Acrílica sobre tela. São José dos Campos, 2019.

Tenho focado bastante também na gravura, gravura em metal e xilogravura, cujos temas também são a paisagem, a urbanidade, o Timor e o Brasil. Parte deste trabalho trata também dos trabalhadores e pessoas simples do cotidiano, tema sobre o qual fiz uma exposição em Díli, no restaurante Pau de Canela, com o nome Um Olhar sobre Timor. 
Também tenho uma série de retratos desenvolvidos durante o ano de 2016, Nomes da Liberdade, uma coleção que teve uma grande exposição na Sala de Leitura Xanana Gusmão. (Trata-se de) Um conjunto no qual retrato os maiores líderes da independência de Timor, também com o intuito de preservar e narrar a história através das pinturas.

Hoje tenho trabalhos em mais ou menos sete países, incluindo Brasil e Portugal. Em 2017, participei de uma exposição internacional no Museu Metropolitano de Tokyo, no Japão. Ano passado, participei de uma exposição internacional de arte contemporânea em Macau, China. Em 2018, também participei da conferência internacional de antropólogos e pesquisadores sobre Timor, a TLSA (Timor Leste Studies Association), com uma exposição Timor Lorosa' e meu pequeno paraíso, de desenhos, pinturas e gravuras.

No Brasil, participo sempre de vários eventos de arte e cultura, principalmente na cidade de São José dos Campos. Sempre que há eventos e exposições, participo.

[Lidiane Maciel] quais suas perspectivas futuras ou sonhos?

[Inu Bere] um Timor digno, onde todas as crianças têm a mesma oportunidade de estudar onde quiserem, têm uma educação de qualidade. Um Timor onde toda família tem um lar, onde possam morar e ter uma vida digna, boa alimentação, acesso à saúde. Um Timor no qual as pessoas sonhem! Sei que é possível, sei que posso contribuir para isso através de arte e educação, sei que isso está acontecendo!

Sonho ser um exemplo para minha geração, tornar-me um artista competente que vive com arte em um país como Timor, ter meu próprio atelier onde posso trabalhar livremente, contribuir para educação de Timor, ganhar o palco internacional das artes e poder apreciar a beleza mágica do meu país, que tanto amo! 


\section{Referências}

BOURDIEU, P. A miséria do mundo. Petropolis. Vozes. 1997.

SANTOS, B.S. Para além do pensamento abissal: das linhas globais a uma ecologia de saberes. In. SANTOS, Boaventura de Souza; MENEZES, Maria Paula. Epistemologia do sul. São Paulo. Editora Cortez. 2010.

Referências: sugerida para conhecer o Timor-Leste

BELO, X. Díli a cidade que não era. Porto. Porto Editora. 2014.

CARDOSO, L. Crônica de uma travessia - A época do ai-dikfunam. Lisboa: Dom Quixote, 1997.

CARDOSO, L. Olhos de Coruja, Olhos de Gato Bravo. Lisboa: Publicações Dom Quixote, 2001.

CARDOSO, L. A última morte do Coronel Santiago. Lisboa: Dom Quixote, 2003.

CARDOSO, L. Requiem Para um Navegador Solitário. Lisboa: Publicações Dom Quixote, 2006.

CINATTI, R; ALMEIDA, L; MENDES, A, S. Arquitetura Timorense. Museu Nacional de Etnologia / Camões - Instituto da Cooperação e da Língua, Lisboa (PT), 2016.

FORGANES, R. Queimado Queimado, Mas Agora Nosso! Timor: Das Cinzas À Liberdade. São Paulo. Labortexto Editorial. 2002.

FONSECA, L, E; ALMEIDA, C. Cooperação internacional e formulação de políticas de saúde em situação pós-conflito: o caso do Timor-Leste. Hist. cienc. saúde-Manguinhos, Rio de Janeiro, v. 22, n. 1, p. 115-141, Mar. 2015. https://doi.org/10.1590/S010459702015000100007.

GUSMÃO, X. Mar Meu. Lisboa (PT). Editor: Granito. 1998.

GUSMÃO, X. Timor Leste, um povo uma pátria. Lisboa (PT) Editor: Edições Colibri. 1994. 
MARTIN, I. Autodeterminação em Timor-Leste: as Nações Unidas, o voto e a intervenção internacional. Trad. Inês Castro. Lisboa: Quetzal. 2001.

NINER, S. Xanana Gusmão. Uma Biografia política. Porto Alegre. Editora Dom Quixote. 2011.

SILVA, K. O governo da e pela kultura. Complexos locais de governança na formação do Estado em Timor-Leste », Revista Crítica de Ciências Sociais [online], 104 | 2014, colocado online no dia 23 setembro 2014, criado a 19 abril 2019. URL: http://journals. openedition.org/rccs/5727; DOI: 10.4000/rccs.5727.

SILVA, K. C. Paradoxos da autodeterminação: a construção do Estado nação e práticas da ONU em Timor Leste. Tese (Doutorado em Antropologia) - Universidade de Brasília, Brasília. 2005.

TAYLOR, J. G. East Timor: the price of freedom. Australia: Pluto Press. 1999.

\section{Documentário:}

SANTOS, L. O Massacre que o Mundo Não Viu. Brasil. Disponível em: https://www.youtube.com/watch?v=0EzQlaG1DmE\&lis$\mathrm{t}=$ PLIPzY18-6TZXuDsUjR9VgEajcqevT7Lff\&index=3\&t=0s\&bpc$\operatorname{tr}=1589036829$. Acesso em 09/05/2020.

\section{Outros sites:}

O Circulador - Redes Culturais na CPLP. - http://www.circulador. com.br/.

Timor Leste - Governo http://timor-leste.gov.tl/. 